THE VELOCITY OF SOUND-WAVES FROM GUN-FIRE IN SOUTHERN CALIFORNIA

\title{
B. Gutenberg
}

Since October, 1937, a sensitive instrument for recording changes in air-pressure has been in operation at the Selsmological Laboratory in Pasadena. The instrument was designed by Dr. H. Benfoff, who will describe it more fully elsewhere. He gives here the following short description of the instrument:

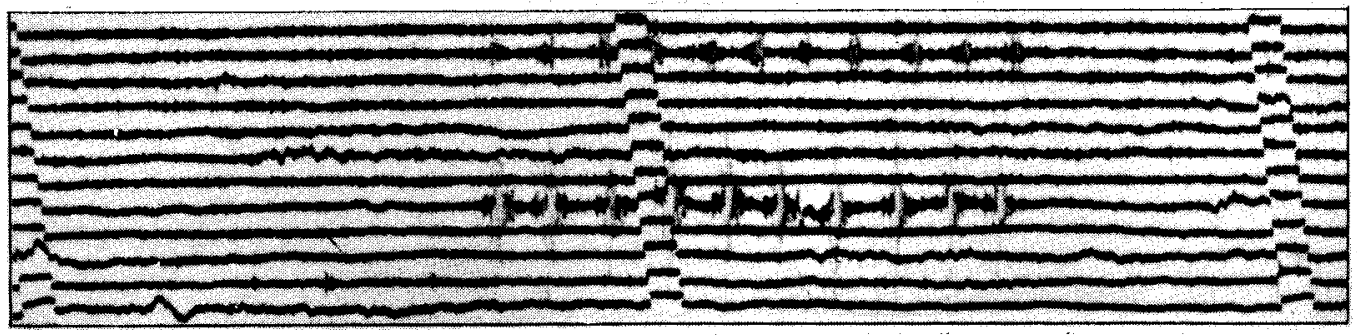

F/G. I-SOUND-WAVES RECOROED BY SHORT-PERIOD BENIOFF BAROGRAPH, PASAOENA, NOVEMBER 9, 1937; TIME INCREASES FROM LEFT TO RIGHT; MINUTE MARK IN UPPER GROUP OF SOUND-WAVES BEGINS AT $g^{h} 5^{m} 22^{s}$, CORRESPONDING MARK IN SECOND GROUP AT $/ 1^{h} 2 l^{m_{22}}$, PACIFIC STANDARD TIME

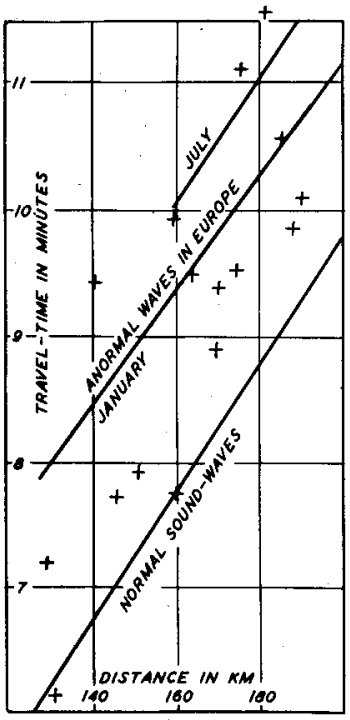

FIG. 2-TRAVEL-TIMES OF SOUNO-WAVES IN SOUTHERN CALIFORNIA, NOVEMBER $9-10$, 1937

"The responding element consists of a permanent magnet movingconductor type loudspeaker mounted in one of the sides of a sealed container of approximately one fifth cubic meter capacity. The effective diameter of the loudspeaker cone is six inches. The natural perlod of vibration of the cone assembly is approximately 150 cycles per second. Hence for frequencies less than 50 cycles per second the cone-displacement is proportional to the atmospheric pressure increment and the electromotive force induced in the coil is proportional to the rate of change of atmospheric pressure. The output-currents are recorded on a standard siesmograph recorder having a galvanometer of 0.25-second period, somewhat over-dampec and a drum-speed of one mm per second at the periphery."

This 1nstrument recorded sound-waves on November 9 and 10, 1937, an example of which is given in Figure 1. As it seemed very probable that these sound-waves originated from gun-fire in target-practice by the United States Navy, a request for detalls was addressed to the Navy. The locations of the liring ships, which were approximately south of Pasadena, were kindly furnished by Captain $\mathrm{H}$. Leary to the nearest minute in longltude and latitude, and the "time of commence firing" and of "cease firing" to the nearest minute. The correlation between these data and the time at which the sound-waves were recorded at Pasadena leaves no doubt that all the instances of recorded impulses like those shown in Figure 1 actually orlginated at this targetpractice. The travel-times for the first sound-waves in each instance are plotted in Figure 2. As may be seen from Figure 2, the observed sound-waves are too late for normal sound-waves by an average of about 1.5 minutes and there are only a lew observations which may belong to normal waves. The points sciatter about the curve found as an average for the propagation of sound-waves in Europe during winter (see, for example, B. Gutenberg, Dle Schallausbreitung in der Atmosphäre, Handbuch Geophysik, v. 9, Berlin, 1932). The scattering of points rarely exceeds 40 seconds. Such differences are to be expected as the time was glven only to the nearest minute. The results leave no doubt that the propagation of sound-waves in the stratosphere here is similar to that in Europe, which means that in all probability the temperature increases in the stratosphere with increasing helght beginning at a level of the order of $30 \mathrm{~km}$, and at higher levels exceeds the temperature near the ground.

In the interim a large number of additional instances of these sound-waves has been recorded in Pasadena. These data pramise further resilts as soon as the data concerning the location of the firing ships and the time of firing are made available by the Navy.

Balch Graduate School of the Geological Sciences (Contribution 253),

California Institute of Technology,

Pesadena, Callfornia 